Short communication

\title{
Shotgun proteomic analysis of the secretome of bovine endometrial mesenchymal progenitor/stem cells challenged or not with bacterial lipopolysaccharide
}

\author{
Carolina Nogueira de Moraes ${ }^{\mathrm{a}, *}$, Leandro Maia ${ }^{\mathrm{a}}$, Eliandre de Oliveira ${ }^{\mathrm{b}}$, \\ Eunice $\mathrm{Oba}^{\mathrm{a}}$ \\ a Department of Animal Reproduction and Radiology, UNESP - São Paulo State University, Botucatu, São Paulo, Brazil \\ b Proteomics Platform, Parc Cientific de Barcelona, Barcelona, Spain \\ ${ }^{c}$ Ross University School of Veterinary Medicine, Department of Clinical Sciences, Basseterre, Saint Kitts and Nevis
} Camila de Paula Freitas Dell'Aqua ${ }^{a}$, Aspinas Chapwanya ${ }^{c}$, Fernanda da Cruz Landim-Alvarenga ${ }^{a}$,

\section{A R T I C L E I N F O}

\section{Keywords:}

Cow

nanoLC-MS/MS

Protein

Uterus

Endometrial mesenchymal cells

\begin{abstract}
A B S T R A C T
The use of the conditioned medium (CM) for diseases treatment is based on its enrichment with biomolecules with therapeutic properties and themselves have a beneficial effect. Secretome of bovine endometrial mesenchymal progenitor/stem cells (eMSCs) using a proteomics approach is until now unknown. This work aimed to evaluate the secretome of bovine eMSCs-CM challenged or not with lipopolysaccharide (LPS). For this, eMSCs characterized were challenged (TG) or not (CG). The CM was collected $12 \mathrm{~h}$ after stimulation and submitted to mass spectrometry analysis. The classification of identified proteins was done by PANTHER according to biological processes, molecular function, cellular component and protein class. 397 protein groups were identified in TG and 302 in CG. We observed positive enrichment for antibacterial response proteins, macrophage activation function, receptor-mediated endocytosis, hydrolase activity, inhibitory enzyme in TG, and for activity structural molecule and intermediate filament cytoskeleton in the CG. Our experimental model shows that eMSCs respond to LPS in the concentration used and can be used to study immune-inflammatory response, besides of the secretion of proteins mainly related to tissue remodeling, immune response and angiogenesis which is an interesting feature for use in cell therapy.
\end{abstract}

\section{Introduction}

In cattle, the endometrium is the main source of mesenchymal progenitor/stem cells (eMSCs), a small proportion of which are undifferentiated with high plasticity (Lupicka et al., 2015). Bovine eMSCs have been studied because of their biological properties, including the paracrine and immunomodulatory effects, which make them promising for use in cell therapy.

Besides the use of MSCs in therapies, the conditioned medium (CM) has a role in the cellular microenvironment, and can exert a therapeutic effect by accelerating organ regeneration processes (Lavoie and RosuMyles, 2013) and tissue repair (Ashiba et al., 2015). MSCs secrete bioactive molecules such as cytokines and growth factors (Ashiba et al., 2015) which are released as soluble molecules or through extracellular vesicles that together are responsible for paracrine (Lavoie and RosuMyles, 2013) and autocrine roles related to the regeneration, angiogen- esis or modulation of immune responses (Skalnikova, 2013)

MSCs are sensitive to culture media and protein profiles may change in response to microenvironments to which they are subjected. The use of different immunological conditions evaluates the therapeutic potential of MSC-derived molecules and make the study of secreted soluble factors important for the understanding its therapeutic effects (Lavoie and Rosu-Myles, 2013). The use of an experimental in vitro model of inflammation using bacterial lipopolysaccharide (LPS) (Lange-Consiglio et al., 2015) makes it possible to evaluate the response of bovine eMSCs facing a stressful insult such as uterine disease.

Interaction of bovine eMSCs-CM is important for understanding how therapeutic approaches can be targeted at the mechanisms by which $\mathrm{CM}$ modulates the endometrium or use of eMSCs to treat reproductive pathologies.

The aim of this study was to evaluate the secretome of bovine eMSCs challenged with bacterial LPS by proteomic analysis

\footnotetext{
* Corresponding author.

E-mail address: carolnmoraes@hotmail.com (C.N. de Moraes).
} 
(nanoLC-MS/MS) using a shotgun strategy. To the best of our knowledge, this is the first report describing the secretome of bovine eMSCs$\mathrm{CM}$ using proteomic analysis.

\section{Material and methods}

The study was approved and performed according to the ethical guidelines of the Institution's Animal Care and Experimentation Ethics Committee (Protocol Number 152/2014).

\subsection{Isolation and culture of bovine eMSCs}

Endometrial cells from bovine endometrial tissue $(n=3)$ in Phase II of estral cycle (Ireland et al., 1980; Chapawanya et al., 2013) were isolated as previously described (Fortier et al., 1988) with modifications. Briefly, samples were digested with $0.3 \%$ trypsin (Sigma ", USA) in HBSS (Thermo Fisher Scientific ${ }^{\circ}$, USA) for $3 \mathrm{~h}$, at $22^{\circ} \mathrm{C}$ under agitation. The samples were then filtered with $40 \mathrm{uM}$ filter (Becton Dickinson ${ }^{\circ}$ and Company, USA). For each sample, a second digestion step was performed with $0.05 \% \mathrm{mg}$ trypsin, $0.05 \%$ collagenase, $0.1 \%$ bovine serum albumin and $0.01 \mathrm{mg}$ DNase I (Sigma ", USA) in HBSS (Thermo Fisher Scientific ${ }^{\circ}$, USA) for $1.5 \mathrm{~h}$ at $37^{\circ} \mathrm{C}$. After filtration, the digesta was washed with HBSS medium and $10 \%$ fetal bovine serum (FBS) (Thermo Fisher Scientific ${ }^{\circ}$, USA) twice and centrifuged at $100 \mathrm{x} \mathrm{g}$ for $10 \mathrm{~min}$. The sediment was plated and cultured at $37.5^{\circ} \mathrm{C}$ in humid atmosphere containing $95 \%$ air and $5 \% \mathrm{CO}_{2}$. The culture medium consisted of DMEM high glucose/F12 (1:2), 20\% FBS, 100IU/mL penicillin, $100 \mu \mathrm{g} / \mathrm{mL}$ streptomycin, $3 \mu \mathrm{g} / \mathrm{mL}$ amphotericin B (Thermo Fisher Scientific ${ }^{\circ}$, USA) and $11 \mu \mathrm{g} / \mathrm{mL}$ amikacin (Teuto ${ }^{\circ}$, BRA). The medium was changed within $18 \mathrm{~h}$ and every 2-3 days thereafter until the culture reached $90 \%$ confluence, and passaged three times.

\subsection{Immunophenotypic characterization}

The immunophenotypic characterization $(n=2)$ was performed by flow cytometry at a LSR Fortessa equipment (BD $\left.{ }^{\circ}, \mathrm{BR}\right)$ using the antibodies anti-CD29 conjugated with Alexa fluor 647 (TS2/16, BioLegend ${ }^{\circ}$, USA), mouse anti-bovine CD-44 conjugated with fluorescein isothiocyanate (FITC) (IL-A118, AbD Serotec, UK), mouse antihorse MHC-II conjugated with FITC (CVS20, AbD Serotec ${ }^{\circ}$, UK), rabbit anti CD-34 conjugated with FITC (polyclonal, Biorbyt ${ }^{\circ}$, USA) and mouse anti-vimentin (v9, AbD Serotec, UK). A secondary goat-anti mouse conjugated with FITC (abcam ${ }^{\circ}$, USA) was used for mouse antivimentin. All these antibodies cross-react with bovine antigens (Moraes et al., 2016). Fluorescence reactions were analyzed using the BD FACSDiva $^{\mathrm{TM}}$ software and were accounted for 10,000 events. The debris population were excluded by gating FSC x SSC at FSC 5000 threshold. Markers with expression levels of $\geq 2 \%$ were considered positive. Data from immunophenotypic characterization is presented as mean and standard error of the mean.

\subsection{Immunocytochemistry characterization}

Immunocytochemistry $(\mathrm{n}=3)$ was performed as previously described (Maia et al., 2013) and the reactions evaluated under an inverted light microscope (Leica Microsystems, GER) using the software Leica Application Suite (LAS), version 4.3.0. The antibodies evaluated were vimentin (1: 200, V9, AbD Serotec $\left.{ }^{\circ}, \mathrm{UK}\right)$, pan-cytokeratin (1: 100, C11, abcam ${ }^{\circ}$, USA) and CD-44 (1: 100, BAG40A, VMRD', USA).

\subsection{Assays for differentiation}

After attaining 95\% confluence, assays for differentiation of adipogenic and osteogenic lineages $(n=3)$ were performed by adding media (StemPro, Thermo Fisher Scientific ${ }^{\circ}$ USA) to the subcultures in triplicate, and also supplementing 5\% rabbit serum (Maia et al., 2013) or $20 \%$ FBS.

Osteogenic differentiation was confirmed on the 14th day when calcium matrix deposits were noted on Alizarin red stains (Sigma, USA). Confirmation of adipogenic differentiation on the 8th day was by presence of intracytoplasmic fat droplets after staining with $0.5 \%$ Oil red (Sigma ${ }^{\circ}$ USA).

\subsection{Challenge of bovine eMSCs with LPS}

For evaluating the protein profile of the secretome, bovine eMSCs were plated on 24 wells $\left(2 \mathrm{~cm}^{2}\right)$ at a density of 1000 cells $/ \mathrm{cm}^{2}$ and cultured with complete maintenance medium (DMEM high glucose/F12 (1:2), 20\% FBS, 100IU/mL penicillin, $100 \mu \mathrm{g} / \mathrm{mL}$ streptomycin, $3 \mu \mathrm{g} /$ $\mathrm{mL}$ amphotericin B; Thermo Fisher Scientific ${ }^{\circ}$, (USA), $11 \mu \mathrm{g} / \mathrm{mL}$ amikacin Teuto ${ }^{\circ}$, (BRA)). After $60-70 \%$ confluence, the cells were cultured in maintenance medium without FBS for $24 \mathrm{~h}$. The control (CG; $n=3$ ) and LPS-stimulated (LPS treated, TG; $n=3$ ) were cultured.

After $12 \mathrm{~h}$, the conditioned medium was collected, filtered through $22 \mu \mathrm{m}$ filter and centrifuged at $2000 \mathrm{~g}$ for $5 \mathrm{~min}$ to remove cellular debris, and the supernatant stored at $-86^{\circ} \mathrm{C}$ for secretome analysis.

\subsection{Secretome analysis by mass spectrometry and liquid chromatography (nanoLC-MS/MS)}

Three biological replicates in both groups (treated vs. control) were analyzed. The samples were digested by initially denaturing in $8 \mathrm{M}$ urea solution (Sigma 51459), followed by reduction with $50 \mathrm{mM}$ dithiothreitol $\left(32{ }^{\circ} \mathrm{C} / 60 \mathrm{~min}\right.$, Sigma 9779$)$. An alkylation step was then performed with $150 \mathrm{mM}$ iodocetamida $\left(25^{\circ} \mathrm{C} / 30 \mathrm{~min}\right.$ in the dark) followed by digestion with trypsin sequence grade $\left(35^{\circ} \mathrm{C}, 16 \mathrm{~h}\right.$, Promega V511A). After digestion, the samples were clean-up with C18 reverse phase and strong cationic-exchange columns (C18, SCX, PolyLC). The samples were then analyzed in a nanoAcquity liquid chromatographer (Waters) coupled to a LTQ-Orbitrap Velos (Thermo Scientific) mass spectrometer.

\subsection{Data analysis}

Thermo Proteome Discover (v.1.4.1.14) was used to search with SequestHT search engine against Mammalia-SwissProt + Bos taurusTREMBL protein database (v. april 2016). The search parameters used were: Enzyme: Trypsin; Missed Cleavage: 2; Precursor and Fragment Mass Tolerances: $10 \mathrm{ppm}$ and $0.6 \mathrm{Da}$, respectively; Variable and Static: Oxidation methionine and Carbamidomethyl cysteine, respectively.

Gene ontology protein classification analysis according biological process (BP), molecular function (MF), cellular component (CC) and protein class (PC) was performed using PANTHER (Protein ANalysis THrough Evolutionary Relationships) Classification System (http:// pantherdb.org/).

\section{Results and discussion}

Bovine eMSCs isolated from uteri in Phase II of the estral cycle were cultured and characterized by immunophenotyping and immunocytochemistry. The cells were also assessed for differentiation potential in addition to being challenged with LPS for secretome analysis using a proteomic approach.

The eMSCs adhered to plastic surfaces within six hours of culture, and showed fibroblastoid morphology after passaging (Fig. 1). Immunophenotypic evaluation by FC revealed high expression for the markers vimentin $(94.35 \% \pm 2.19)$, CD-29 (99.85\% \pm 0.07$)$ and CD-44 (96.9\% \pm 2.40$)$. Similar to previous studies (Xiong et al., 2014), there was low expression of the CD-34 $(4.25 \% \pm 1.06)$ marker, and no expression of the MHC-II marker $(1.05 \% \pm 0.78)$ (Fig. 2). After evaluating for osteogenic and adipogenic potential, the eMSCs cells 

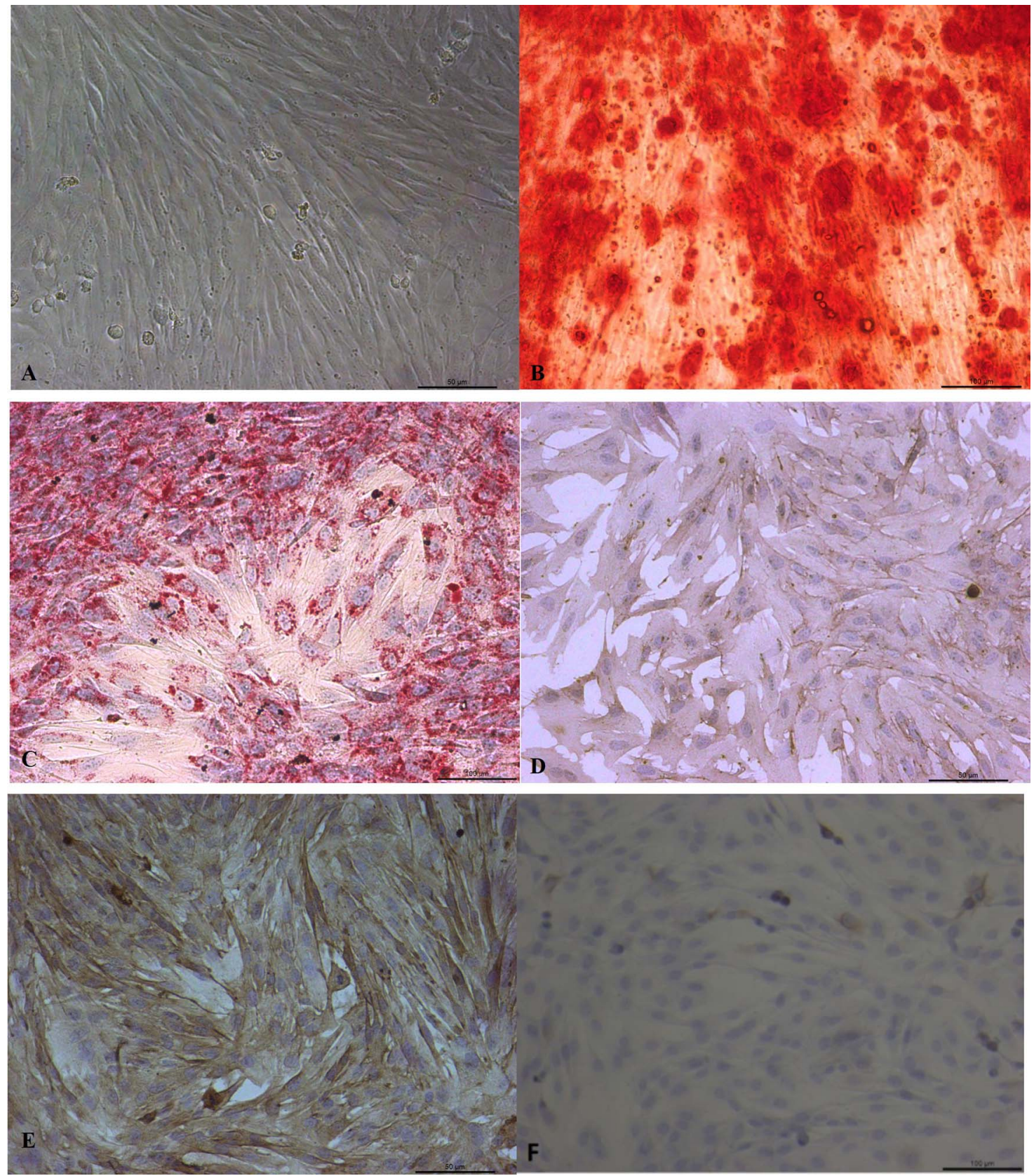

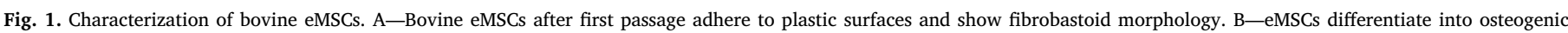

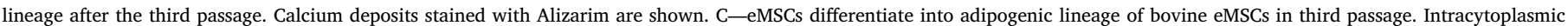

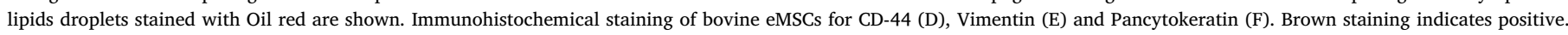

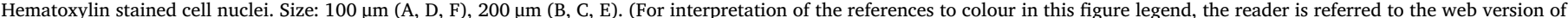
this article.)

stained positive, similar to previous finding (Lupicka et al., 2015). Similarly, other authors reported positive staining for the markers CD44 in bovine endometrial putative mesenchymal cells on immunocytochemistry (Cabezas et al., 2014), and for vimentin in human eMSCs (Kato, 2012) (Fig. 1). Here, some endothelial epithelial cells were positive for pan cytokeratin, which showed that there were no cell morphology alterations after culture.

A proteomic analysis was performed in order to find more information on the protein content of the secretome of bovine eMSCs. A shotgun approach was used and the LC-MS/MS detected a total of 397 proteins groups on TG and 302 on CG with 242 commons between the groups (Fig. 3). Many proteins belonging to the immune system, angiogenic processes, antioxidant and tissue remodeling pathways were detected in the TG (Table 1).
Our in vitro experimental model showed that the cells respond positively and in a protective manner after stimulation with LPS. It can be inferred, for instance, from the presence of arginase I and heat shock proteins, that these proteins protect cells or tissues from stress (Frier and Locke, 2007) by stabilizing and repairing proteins (Fan, 2012). This response is characteristic of a defense mechanism via the secretion of crucial proteins for tissue restoration, or protection from tissue injury. This suggests that CM alone or together with MSCs can be an efficient alternative to assist in healing (Ashiba et al., 2015).

MSCs are sensitive to culture media and may change their proteomic profiles in response to the microenvironments in which they are subjected (Lavoie \& -Rosu Myles, 2013). It is noteworthy that in the CM of CG, there were proteins with antimicrobial or antifungal activity, and also tissue remodeling (Table 1 ). The presence of these proteins in 

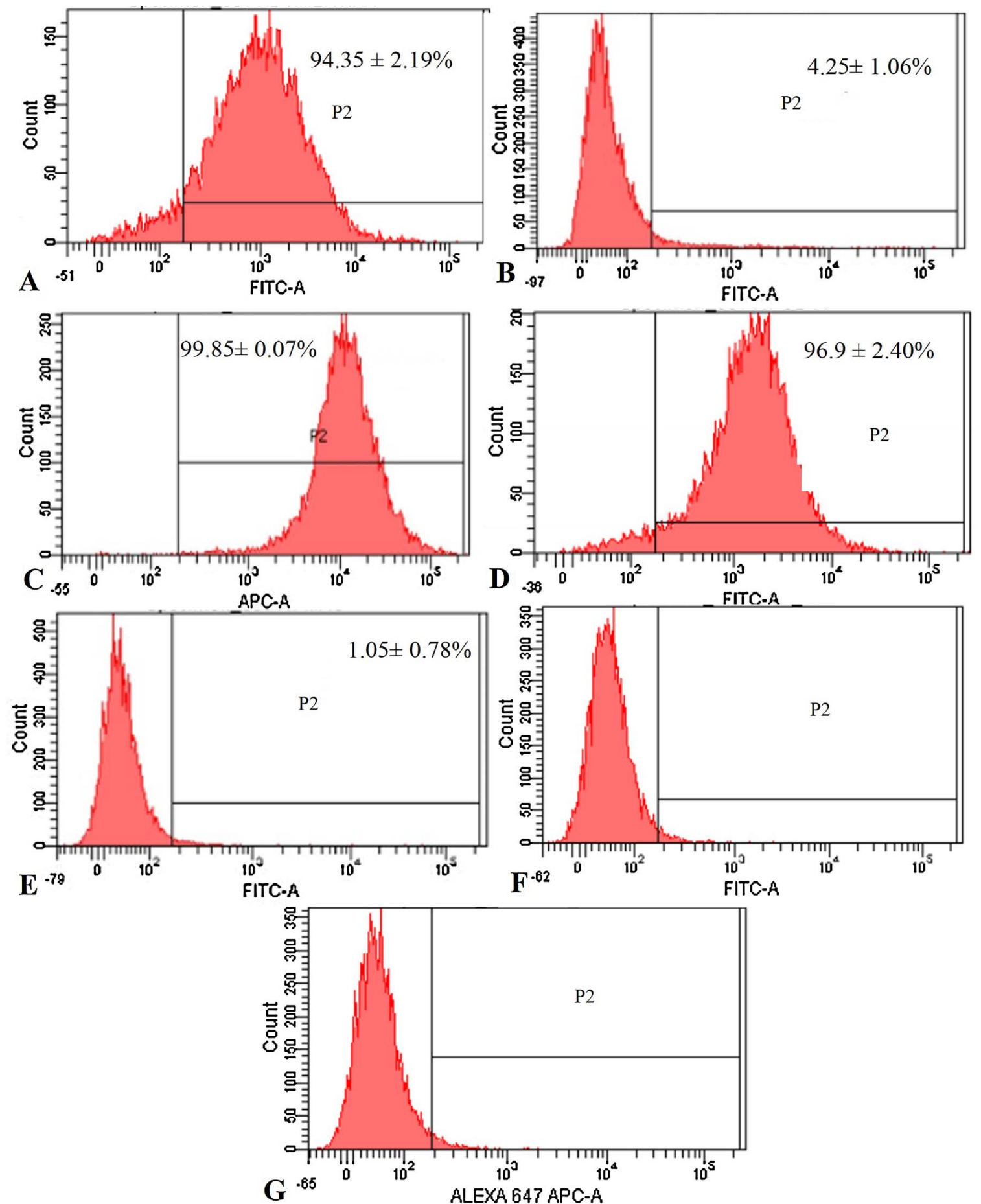

Fig. 2. Histograms of the bovine eMSCs cytomarkers analyzed by flow cytometry. A - Vimentin; B - CD34; C - CD29; D - CD44; E - MHC-II; F and G: controls.

the $\mathrm{CM}$ of $\mathrm{CG}$, even without stimulation, could be promising to demonstrate the great potential and possibility of using this medium for use as therapeutics. In humans, the CM of MSCs from dental pulp was efficient in the experimental treatment of multiple sclerosis and even showed similar effects of treatment with their own MSCs (Shimojima et al., 2016).

A protein with antioxidant activity (peroxiredoxin-6, Table 1) was found in TG. This antioxidant capacity of the CM was previously reported for restoring or reducing retinal functions in diabetes animal model (Duarte et al., 2016).

Recently, Lange-Consiglio et al. (2015) showed in an experimental equine uterine inflammation model that horse amniotic MSCs-CM significantly reduce the expression of MMP-1 and MMP-13. These genes modulate inflammatory pathways. Also, in humans, CM of uterine cervical stem cells showed to have anti-inflammatory and bactericidal roles (Bermudez et al., 2015) and the eMSCs showed a potential to be used at pelvic organ prolapse once cells can induce the immune response and help at the tissue reorganization (Emmerson and Gargett, 2016). In our study, anti-inflammatory proteins (such as granulins, Table 1) were found in TG. In addition, in vitro use of the $\mathrm{CM}$ associated with endometrial cells resulted in improvement of the proliferation rate, showing the relevance of soluble factors produced by MSCs and its potential to increase cell replacement (Corradetti et al., 2014). Such studies support using CM as an alternative for treating 


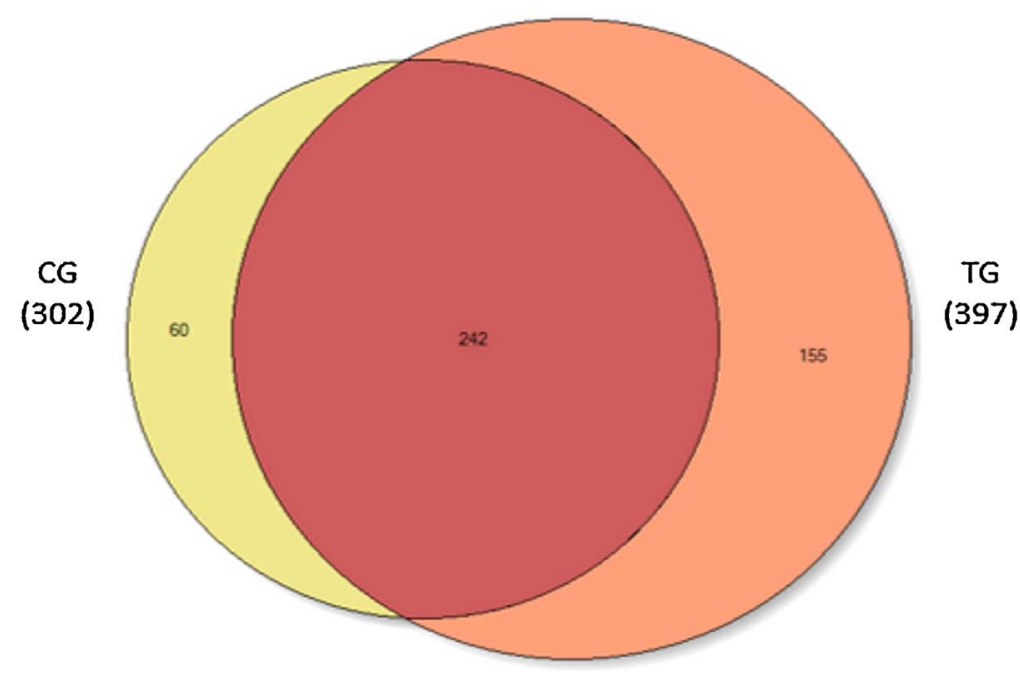

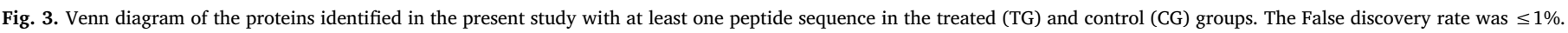

uterine diseases causing low fertility in cattle.

To better characterize the CM proteome, we performed some classification on the identified proteins using Gene Ontology tools (http://geneontology.org/). The Panther GO analysis identified positive enrichment (PE) for BP in macrophage activation function (GO:
0042116, fold enrichment, $\mathrm{FE}=7.87$ ) and receptor-mediated endocytosis (GO: 0006898, FE $=5.23$ ) in TG. Regarding MF, there was PE for hydrolase activity (GO: 0016787; FE $=1.87$ ) and inhibitory enzyme (GO: 0004857; FE $=5.15$ ) in the TG, and activity structural molecule (GO: 0005198; FE $=2.73$ ) in the CG. For CC, enrichments were verified

Table 1

Proteins with more than two PCMs differently expressed in the treated (TG) and control (CG) groups. These proteins have mainly tissue repair and immunomodulatory roles.

\begin{tabular}{|c|c|c|c|c|}
\hline Biological Functions & Swiss-Prot accession & Protein name & Gene name & Group \\
\hline \multirow[t]{7}{*}{ Immune response } & Q9UGM3 & Deleted in malignant brain tumors 1 protein & DMBT1 & Control \\
\hline & KRT16 & Uncharacterized protein & GP340 & Control \\
\hline & P01857 & Ig gamma- 1 chain $C$ region & KRT16 & Control \\
\hline & A5A6M2 & Annexin A1 & IGHG1 & Control \\
\hline & P01876 & Ig alpha- 1 chain $C$ region & ANXA1 & Control \\
\hline & P01834 & Ig kappa chain $\mathrm{C}$ region & IGHA1 & Control \\
\hline & & & IGKC & \\
\hline \multirow[t]{14}{*}{ Antimicrobian/antifungal activity } & P03973 & Antileukoproteinase & SLPI & Control \\
\hline & P59665 & Neutrophil defensin 1 & DEFA1 & Control \\
\hline & P06702 & Protein S100-A9 & S100A9 & Control \\
\hline & P01857 & Ig gamma-1 chain $\mathrm{C}$ region & IGHG1 & Control \\
\hline & Q3T0Z0 & Uncharacterized protein (WAP four-disulfide core domain 2) & WFDC2 & Control \\
\hline & P81644 & Apolipoprotein A-II & APOA2 & Treated \\
\hline & G3N3P6 & Cystatin & N/A & Treated \\
\hline & F1MI18 & Uncharacterized protein & N/A & Treated \\
\hline & F1MNV5 & Kininogen-1 & $\mathrm{N} / \mathrm{A}$ & Treated \\
\hline & F1MVS9 & Uncharacterized protein & KNG1 & Treated \\
\hline & P31944 & Caspase 14 & MASP1 & Treated \\
\hline & A2I7M9 & Serpin A3-7 & CASP14 & Treated \\
\hline & Q1JPB0 & Leukocyte elastase inhibitor (LEI) & SERPINA3-2 & Treated \\
\hline & & & SERPINB1 & \\
\hline \multirow[t]{3}{*}{ Anti-inflammatory activity } & A5A6M2 & Annexin A1 & ANXA1 & Control \\
\hline & P06702 & Protein S100-A9 & S100A9 & Control \\
\hline & P28799 & Granulins & GRN & Treated \\
\hline \multirow[t]{7}{*}{ Tissue remodeling } & A5A6M2 & Annexin A1 & ANXA1 & Control \\
\hline & E2DI12 & Syndecan-1 (Fragment) & SDC1 & Control \\
\hline & P28799 & Granulins & GRN & Treated \\
\hline & P50757 & $72 \mathrm{kDa}$ type IV collagenase & MMP2 & Treated \\
\hline & E1B726 & Plasminogen & PLG & Treated \\
\hline & F1N2Y2 & Uncharacterized protein & COL5A2 & Treated \\
\hline & E1B726 & Plasminogen & PLG & Treated \\
\hline \multirow[t]{3}{*}{ Angiogenic activity } & P80929 & Angiogenin-2 & ANG2 & Treated \\
\hline & Q2KIF2 & Leucine-rich alpha-2-glycoprotein 1 & LRG1 & Treated \\
\hline & P50757 & $72 \mathrm{kDa}$ type IV collagenase & MMP2 & Treated \\
\hline Protective activity & E9RHW1 & Heat shock $27 \mathrm{kDa}$ protein 1 & HSPB1 & Treated \\
\hline Antioxidant & P86215 & Peroxiredoxin-6 & PRDX6 & Treated \\
\hline Other functions & A0SXL6 & Elongation factor 2 (EF-2) & EEF2 & Control \\
\hline Cell/cell adhesion & A7YWB6 & Transforming growth factor-beta-induced protein ig-h3 & TGFBI & Treated \\
\hline Adhesion/cell aggregation & A5PJE3 & Fibrinogen alpha chain & FGA & Treated \\
\hline Platelet aggregation & P05997 & Collagen alpha-2(V) chain & COL5A2 & Treated \\
\hline Extracellular matrix constituent & Q61245 & Collagen alpha-1(XI) chain & COL11a1 & Treated \\
\hline
\end{tabular}


in both groups to extracellular matrix (GO: 0031012) and extracellular region (GO: 0005576), as well as intermediate filament cytoskeleton (GO: 0045111) in the CG. Interestingly, with respect to PC we evidenced PE in antibacterial response proteins (PC00051; FE $=5.87$ ) in the TG.

Here we observed proteins with anti-inflammatory, antibacterial properties and related to tissue remodeling in both $\mathrm{CM}$ which leads us to believe that these cells respond to many stimuli to defend the organisms. Thus, eMSCs and CM may have a role in treating reproductive tract diseases in cattle. Also, our results, especially based on protein enrichment to macrophage activation and identification of large number of proteins related to immune response on TG, allow us to infer that our in vitro model of stimulation with bacterial LPS of bovine eMSCs is effective to study immune and inflammatory response.

\section{Acknowledgements}

The authors thank the Proteomics Platform of the Barcelona Science Park. We are also indebted to PRB2, ProteoRed-ISCIII, the Spanish Proteomics network. This work was supported by Fundação de Amparo à Pesquisa do Estado de São Paulo [Proc.2014/20447-2, Proc. 2015/ 18964-1, Proc.2015/01057-1].

\section{References}

Ashiba, K., Terunuma, A., Terunima, H., Takane, T., Deng, X., Yamashita, Y., Watanabe, K., 2015. Immortalized mesenchymal stem cells producing conditioned medium in a large scale for $-\mathrm{t}$, herapeutic useage. Inflamm. Regen. 35, 57-60. http://dx.doi.org/ 10.2492/inflammregen.35.057.

Bermudez, M.A., Sendon-Lago, J., Eiro, N., Trevino, M., Gonzales, F., Yebra-Pimentel, E., Giraldez, M.J., Macia, M., Lamelas, M.L., Saa, J., Vizoso, F., Perez-Fernandez, R., 2015. Corneal epithelial wound healing and bactericidal effect of conditioned medium from human uterine cervical stem cells. Cornea 56 (2), 983-992. http://dx. doi.org/10.1167/iovs.14-15859.

Cabezas, J., Lara, E., Pacha, P., Rojas, D., Veraguas, D., Saravia, F., Rodríguez-Alvarez, L., Castro, F.O., 2014. The endometium of cycling cows contains populations of putative mesenchymal progenitor cells. Reprod. Dom. Anim. 49, 550-559. http://dx.doi.org/ 10.1111/rda.12309.

Chapawanya, A., Meade, K.G., Doherty, M.L., Callanan, J.J., O'Farrelly, C., 2013. Endometrial epithelial cells are potent producers of tracheal antimicrobial peptide and serum amyloid A3 gene expression in response to $E$. coli stimulation. Vet. Immunol. Immunopathol. 151, 157-162. http://dx.doi.org/10.1016/j.vetimm.2012. 09.042 .
Corradetti, B., Correani, A., Romaldini, A., Marini, M.G., Bizarro, D., Perrini, C., Cremonesi, F., Lange-Consiglio, A., 2014. Amniotic membrane-derived mesenchymal cells and their conditioned media: potential candidates for uterine regenerative therapy in the horse. PLoS One 9, 1-9. http://dx.doi.org/10.1371/journal.pone. 0111324.

Duarte, D.A., Papadimitriou, A., Gilbert, R.E., Thai, K., Zhang, Y., Rosales, M.A.B., Faria, J.B.L., Faria, J.M.L., 2016. Conditioned medium from early- outgrowth bone marrow cells is retinal protective in experimental model of diabetes. PLoS One 11, 1-15. http://dx.doi.org/10.1371/journal.pone.0147978.

Emmerson, S.J., Gargett, C.E., 2016. Endometrial mesenchymal stem cells as a cell based therapy for pelvic organ prolapse. World J. Stem Cell 8, 202-215. http://dx.doi.org/ 10.4252/WJSC.v8.i5.202.

Fan, G.C., 2012. Role of heat shock proteins in stem cell behavior. Prog. Mol. Biol. Transl. Sci. 11, 305-322. http://dx.doi.org/10.1016/B978-0-12-398459-3.00014-9.

Fortier, M.A., Guilbault, L.A., Grasso, F., 1988. Specific properties of epithelial and stromal cells from the endometrium of cows. J. Reprod. Fert. 83, 239-248.

Frier, B.C., Locke, M., 2007. Heat stress inhibits skeletal muscle hypertrophy. Cell Stress Chapereones 12, 132-141. http://dx.doi.org/10.1379/CSC-233R.1.

Kato, K., 2012. Stem cells in human normal endometrium and endometrial cancer cells: characterization of side population cells. Kaohsiung J. Med. Sci. 28, 63-71. http://dx. doi.org/10.1016/j.kjms.2011.06.028.

Lange-Consiglio, A., Perrini, C., Esposti, P., Derigibus, M.C., Camussi, G., Pascucci, L., Marini, M.G., Corradetti, B., Bizarro, D., Cremonesi, F., 2015. Effects of microvesicles secreted from equine amniotic-derived progenitor cells on in vitro lipopolysaccharide-treated tendon and endometrial cells. Reprod. Fertil. Dev. 28, 244-245. http://dx.doi.org/10.1071/RDv28n2Ab226.

Lavoie, J.R., Rosu-Myles, M., 2013. Uncovering the secretes of mesenchymal stem cells Biochimie 95, 2212-2221. http://dx.doi.org/10.1016/j.biochi.2013.06.017.

Lupicka, M., Bodek, G., Shpigel, N., Elnekave, E., Korzekwa, A.J., 2015. Identification of pluripotent cells in bovine uterus: in situ and in vitro studies. Reproduction 149, 317-327. http://dx.doi.org/10.1530/REP-14-0348.

Maia, L., Landim-Alvarenga, F.C., Mota, L.S.L.S., Golim, M.A., Laufer-Amorim, R., De Vita, B., Barberini, D.J., Listoni, A.J., Moraes, C.N., Heckler, M.C.T., Amorim, R.M., 2013. Immunophenotypic, immunocytochemistry, ultrastructural and cytogenetic characterization of mesenchymal stem cells from equine bone marrow. Micros Res. Tech. 76, 618-624. http://dx.doi.org/10.1002/jemt.22208.

Moraes, C.N., Maia, L., Camargos, M.D., Freitas-Dell Aqua, C.P., Mota, L.S.L.S., Chapwanya, A., Landim-Alvarenga, F.C., Oba, E., 2016. Bovine endometrial cells: a promising source of mesenchymal stem/progenitor cells. Cell Biol. Int. 40, 1332-1339. http://dx.doi.org/10.1002/cbin.10688.

Shimojima, C., Takeuchi, H., Jin, S., Parajuli, B., Hattori, H., Suzumura, A., Hibi, H., Ueda, M., Yamamoto, A., 2016. Conditioned medium from the stem cells of human exfoliated deciduous teeth ameliorates experimental autoimune encephalomyelitis. J. Immunol. 15, 4164-4171. http://dx.doi.org/10.4049/jimmunol.1501457.

Skalnikova, H.K., 2013. Proteomic techniques for characterization of mesenchymal stem cell secretome. Biochimie 95, 2196-2211. http://dx.doi.org/10.1016/j.biochi.2013. 07.015 .

Xiong, H., Bai, C., Wu, S., Gao, Y., Lu, T., Hu, Q., Guan, W., Ma, Y., 2014. Biological characterization of mesenchymal stem cells from bovine umbilical cord. Anim. Cells Syst. 18, 56-67. http://dx.doi.org/10.1080/19768354.2014.880370. 